\title{
The Influence of Pencil Graphite Hardness on Voltammetric Detection of Pentachlorophenol
}

\author{
Katarzyna Skrzypczyńska ${ }^{1}$, Krzysztof Kuśmierek ${ }^{1}$, Andrzej Świątkowski ${ }^{1}$, Lidia Dąbek ${ }^{2, *}$ \\ ${ }^{1}$ Institute of Chemistry, Military University of Technology, Kaliskiego 2, 00-908 Warsaw, Poland, \\ ${ }^{2}$ Faculty of Environmental, Geomatic and Energy Engineering, Kielce University of Technology, al. \\ Tysiąclecia Państwa Polskiego 7, 25-314 Kielce, Poland, \\ E-mail: 1dabek@tu.kielce.pl
}

doi: $10.20964 / 2018.01 .100$

Received: 8 July 2017 / Accepted: 8 September 2017 / Online Published: 1 December 2017

\begin{abstract}
A pencil graphites were used for detection of pentachlorophenol (PCP) based on differential pulse voltammetry (DPV) and cyclic voltammetry (CV). The voltammetric studies were carried out using a pencil graphite electrode (GPE), carbon paste electrode (CPE) and powdered electrode (PE). The pencil graphites were characterized with scanning electron microscope (SEM), Raman spectroscopy and powder X-ray diffraction (XRD) methods. The effects of deposition potential, scan rate and pulse amplitude were examined to optimize the differential pulse voltammetry conditions. Compared to the other working electrodes the graphite pencil electrodes were recognized by their low cost, simplicity, commercial availability and ease of modification. The voltammetric studies have shown the usefulness of the pencil graphite as an electrode material. Their electrochemical usability increased with decreasing hardness $(2 \mathrm{~B}>5 \mathrm{~B}>8 \mathrm{~B})$.
\end{abstract}

Keywords: graphite pencil electrode, carbon paste electrode, pentachlorophenol, voltammetric determination

\section{$\underline{\text { FULL TEXT }}$}

(C) 2018 The Authors. Published by ESG (www.electrochemsci.org). This article is an open access article distributed under the terms and conditions of the Creative Commons Attribution license (http://creativecommons.org/licenses/by/4.0/). 